\section{KEY POINTS}

- India, Indonesia, and Malaysia are early adopters in accrediting online courses from other universities and from platform-based course providers such as massive open online courses.

- This paradigm shift to accreditation of online courses was enabled by progressive policies and regulatory frameworks in India, Indonesia, and Malaysia, which allow up to $30 \%$ to $40 \%$ of graduating credits from external online courses.

- The European Union is another early adopter, with credit transfer from online courses determined by the respective universities following the framework of the European Credit Transfer and Accumulation System, which suggests potential for regional cooperation in Asia and the Pacific.

- Indonesia's Cyber Education Institute developed a digital credentialing system enabled by blockchain technology with capability to securely issue, stack, store, verify, and share academic credentials.

- Online course marketplaces that specifically group credit-bearing courses have been organized in the European Union, India, and Indonesia.
ISBN 978-92-9269-113-4 (print)

ISBN 978-92-9269-114-1 (electronic)

ISSN 2071-7202 (print)

ISSN 2218-2675 (electronic)

Publication Stock No. BRF210411-2

DOI: http://dx.doi.org/10.22617/BRF210411-2

\title{
Accreditation of Online Courses in Higher Education-Early Adopters in the European Union, India, Indonesia, and Malaysia
}

\author{
Marito Garcia \\ Fellow \\ Darden Business School \\ Center for Global Initiatives \\ University of Virginia
}

Ryotaro Hayashi

Social Sector Economist

Human and Social Development

Division, South Asia Department

Asian Development Bank

\author{
Lynnette D. Perez \\ Principal Education Specialist \\ Human and Social Development \\ Division, Southeast Asia Department \\ Asian Development Bank
}

\section{INTRODUCTION}

The year 2020 marked a significant turning point in the history of education, in which online learning surged in importance as school systems scrambled to adapt to social distancing brought about by the coronavirus disease (COVID-19) pandemic. This switch could have a lasting impact on education systems as they shift toward a blended-learning approach that combines online and in-class learning.

Online courses have become more dominant in the COVID-19 pandemic, and in the context of Sustainable Development Goal 4, which aims to ensure inclusive and equitable quality education and promote lifelong learning opportunities for all. The Qingdao Declaration (2015) also emphasized the role of online learning and massive open online courses (MOOCs) to build new learning pathways toward tertiary education and lifelong learning. Furthermore, the role of online courses is promoted in global conventions on the recognition of qualifications concerning higher education (UNESCO 2020).

Note: This brief was peer reviewed by Paul Vandenberg, Senior Economist, Economic Research and Regional Cooperation Department, Asian Development Bank (ADB); and Jian Xu, Senior Education Specialist (Education Technology), Sustainable Development and Climate Change Department, ADB. The authors are grateful for the review and inputs from Unika Shrestha, Social Sector Specialist, South Asia Department, ADB; and assistance provided by Alfredo Pasoquin Garcia, Associate Project Analyst, South Asia Department, ADB. The views expressed by the authors do not necessarily reflect the views of the governments of India, Indonesia, and Malaysia, nor of the European Union. 
Many online courses are offered by higher education institutions worldwide, not only in the European Union (EU) and the United States (US) where they are most prevalent. In the US for instance, the Massachusetts Institute of Technology (MIT) offers its MITx courses not only to its students but also to universities in other countries. Beginning around 2012, universities began to offer their online courses to outside learners as MOOCs hosted in online platform managers like Coursera, edX, FutureLearn, etc. The online platform managers collaborated with individual universities worldwide to form partnerships that deliver these online courses. These online courses do not necessarily offer credit, unless the country's higher education systems, or the universities within these countries recognize them as credit-bearing. However, these online courses can be branded by the online platform managers as "verified courses" or what Coursera or edX call "accredited certificates" issued upon successful completion and passing of assessments embedded in the course program. These "accredited certificates" are digitally signed and issued by the online platform managers and the participating university. Thus, these online platform managers do not create their own material. They partner with the world's top universities (and lately with private sector companies and professional organizations) to develop these MOOCs and online courses.

At present, tertiary education systems around the world typically have no formal structures in place for recognizing credits in online courses that are not offered by their own institutions. This brief examines the experiences of the EU, India, Indonesia, and Malaysia-early adopters in recognizing online courses from other institutions and MOOCs-with a view to extracting lessons on qualifying earned credits for academic programs.

\section{THE NEW NORMAL IN LEARNING AND EDUCATION}

The COVID-19 pandemic forced schools to close around the world, as 1.5 billion students suddenly switched from classroom teaching to online learning (UNESCO 2021). In Sri Lanka, a survey conducted by the Asian Development Bank (ADB) in June 2020 showed that during the COVID-19 pandemic, more than $90 \%$ of higher education institutions (state and nonstate) carried out mostly online remote learning (Hayashi et al. 2020). In Japan, 90\% of universities were providing distance learning as of June 2020 (MEXT 2020), while in upper-middle-income countries, $88 \%$ of youth continued learning through online video lectures and/or online testing (International Labour Organization 2020).

Under the "new normal" in the postpandemic era, the practice of online learning is expected to grow and become a more significant part of the education system, especially in postsecondary education. Indeed, asynchronous learning through online courses from country online platforms and
MOOCs from global online platforms increased dramatically during the school closures. Between December 2019 and December 2020, enrollment in major online platforms such as Coursera, edX, and FutureLearn surged. Coursera, which is a leading online course platform based in Silicon Valley, boosted enrollment from 45 million in 2019 to 76 million in 2020, while edX enrollment increased from 24 million to 35 million users over the same period (Class Central 2020). Adoption of the blended learning model (partly in-classroom and partly online) is also likely to increase. In Sri Lanka, for example, higher education students and faculty found blended learning to be beneficial and appropriate for most courses of study (Hayashi et al. 2020).

Even before COVID-19 struck in 2020, a few developing countries had already made significant commitments to online programs and technology, which turned out to be an appropriate remedy for educational systems to recuperate from pandemicinduced learning deficits. The early adopter case studies in this brief clearly benefited from their experiences, especially India whose online course enrollment dramatically increased particularly from its own digital platform called Study Webs of Active-Learning for Young Aspiring Minds (SWAYAM). These variations in practices for transferring credits across the pioneering countries, particularly the rules on which courses are credit-bearing, and which courses are obtained from a countrylevel platform or from other online platforms, are further explored in this brief.

\section{BENEFITS AND CHALLENGES OF CREDIT TRANSFERS FROM ONLINE COURSES}

Credit transfers of online courses could bring three benefits. First, using online course credits can expand access to higher education without the need to construct new classrooms. This can allow significant resource savings while increasing access to higher education. A university can accommodate higher enrollment with existing physical facilities through blended learning, as observed in recent case studies in the US. In a study of five universities, the average class size of online classes was 19\%-80\% larger than face-to-face classes. In Arizona State University for example, class size in online courses was a few times larger than face-to-face classes (Arizona State University Action Lab and Boston Consulting Group 2018).

Second, online credit-bearing courses contribute to improving access to quality education by taking advantage of content developed by the world's leading experts and the best professors. Online learning is most impactful where technologies are changing fast and where the diffusion of knowledge can move faster. In developing countries, training professors in new areas such as artificial intelligence, machine learning, biotechnology, nanotechnology, and blockchain is difficult. The largest beneficiaries of this new way of receiving education are universities that lack 
good professors - particularly those outside major cities in most developing countries; as well as those in smaller countries such as Bhutan, Luxembourg, Sri Lanka, and countries in the Caribbean and the Pacific.

Third, the recognition of online courses or MOOCs as transfer credit in universities can reduce the unit cost of credit-bearing courses, thereby reducing overall cost of tertiary education. A cost-benefit analysis of online versus in-person teaching in the US showed that online courses cost anywhere from $8 \%$ to $50 \%$ less per student credit-hour in five case studies conducted in 2017-2018 (Arizona State University Action Lab and Boston Consulting Group 2018).

As Scott Galloway observes in his book Post Corona: From Crisis to Opportunity (Galloway 2021) the heart of the coming transformation of higher education is technology. Online instruction can provide learning opportunities that classrooms do not, but also because online education does something else. It scales. And that scale will allow individual institutions-and individual professors - to expand their reach exponentially. This provides the potential to correct one of the great inequities of the last half-century - the artificial scarcity of elite education.

However, wider adoption of a credit-transfer scheme for online courses would need to address a number of challenges. Course credits represent learning based on defined learning outcomes and their associated workload. Accreditation is a formal process of quality control and can differ by context and mode of learning, thereby requiring some standardization. This includes concerns related to the quality of online learning, which varies significantly from one provider to another. For example, online learning can range from bona fide open institutions that provide qualityassured programs and have full degree awarding authority to unaccredited course providers without clearly defined quality assurance procedures (UNESCO 2020). A related challenge is to determine who is responsible for assessments for any given course or program. In that sense, the role of quality assurance is critical. There is a need to determine if the provider and online course program belong to the system of higher education in the country, or are from authoritative sources of information.

The challenge of quality assurance is also demonstrated by the wide variation in the rigor and detail of the rules and guidelines for credit transfers across the pioneering countries. The Malaysian accreditation system and the European Credit Transfer and Accumulation System (ECTS) have more developed guidelines in awarding course credits compared with the Indian and Indonesian system. In the Malaysian credit transfer system, rules with respect to quality of MOOCs and online courses, authentication of applicant's identity, and verification of learning attainment over several types of learning assessments are enforced with testing, which are either outside the purview of the MOOCs themselves, or are part of the formative or summative assessments embedded in these MOOCs. In the European system, what constitutes as a course credit award is well articulated, in contrast to the Indian or Indonesian system. In the ECTS, the volume of learning is more sharply measured and is based on defined learning outcomes and their associated workload. Thus, for example, one credit is based on 25-30 hours of course participation inclusive of all learning activities such as lectures, seminars, projects, and practical works.

Lastly, a major challenge to online course delivery is that of connectivity to the internet and access to devices like laptops and smartphones. ADB online surveys in Bangladesh and Sri Lanka clearly demonstrated that the main challenges to the delivery of online courses are access to these infrastructure and student devices, poor quality of internet video and/or audio connection, high cost of broadband internet, challenges for hands-on laboratory-related coursework, unsatisfactory student assessment methods, and lack of student-teacher engagement (Hayashi et al. 2020). The sudden shift to remote learning delivery showed that in these countries, the mode of student-teacher engagement used mostly smartphones (90\%) and only $60 \%$ had laptops or desktop computers to study, carry out assignments, or undertake research - a challenging learning environment, particularly for students from low-income households. Furthermore, most faculty were unpreparedabout $67 \%$ of faculty in Sri Lanka said that they need help in the use of technology tools, and $49 \%$ wanted more training in online pedagogy.

\section{CASE STUDIES IN AWARDING CREDITS TO ONLINE COURSES}

While MOOCs and online courses reached a new milestone of 180 million learners in 2020 (Class Central 2020), tertiary education systems worldwide mostly did not have a formal structure to recognize online courses via a credentialing process for awarding academic qualifications.

India, Indonesia, and Malaysia are among the first movers in the world, implementing reforms in their regulatory systems to integrate online courses and MOOCs into their overall academic curriculums. Likewise, the European Commission established policies to allow learners from each of its 27 member countries to earn and accumulate credits through online courses with validity in the universities across EU member states.

Malaysia was the first country to institute academic credentials for online MOOCs in 2016, as part of its Malaysian Education Blueprint for 2015-2025, which it categorized as Shift 9: Globalized Online Learning. The Globalized Online Learning initiative aims to enhance the quality of course content and cut the cost of course delivery, while bringing Malaysian expertise worldwide for global consumption. Malaysia's credit transfer for MOOCs seeks to support the Globalized Online Learning initiative and recognize MOOCs as a legitimate and reliable vehicle for learning, by providing recognition through credit. 
India's policy framework, also issued in 2016, encourages online learning through SWAYAM. This is a MOOC platform where online courses are developed by India's leading universities and centers of excellence. The platform can be accessed by university students across India so that they can customize courses for their own degree programs.

In Indonesia, the government is determined to improve Indonesian competitiveness worldwide by placing high priority on the development of science, technology, and innovation in light of the fourth industrial revolution or Industry 4.0. With the support of online learning, the government aims to increase access to tertiary education from 34\% in 2018 to 50\% in 2026, while improving course quality (Ministry of Education and Culture Regulation No. 7 of 2020). A new regulation was enacted in 2018 and then updated in 2020 to firmly establish online learning's receipt of credit for academic qualification. At the same time, the government set up a platform consortium of university online course providers called Indonesia Cyber Education Institute (ICE), where students can earn credit through online courses.

In the EU, 27 member countries are party to an interlinked system of course credit transfers called the ECTS. Since 1989, ECTS has provided systematic recognition of courses in higher education institutions in the EU member states. This credit transfer system was set up for students who studied in person in other countries, and ECTS enabled to transfer those credits back to their home institution. This mechanism was extended to online courses; thus, credit units could be awarded to online courses taken from other institutions. In other words, the new online course transfer mechanism was built around the existing ECTS of transferring credits already in place.

\section{A. Malaysia}

Malaysia is the fifth largest economy in Southeast Asia and aims to become a high-income country by the early 2020s (International Monetary Fund 2020). Its newly industrialized, robust market economy is supported by a highly educated workforce.

The country's secondary education gross enrollment, at $84 \%$, is one of the highest in Asia, and its literacy rate is $95 \%$ for those above the age of 15 (World Bank 2020). In tertiary education, Malaysia's gross enrollment ratio increased from 39\% in 2014 to 43\% in 2019 after the country adopted its Education Blueprint, 2015-2025 (Ministry of Education 2015). It plans to achieve gross tertiary enrollment of $48 \%$ by 2025 . Innovations in research within its higher education system now rank Malaysia 27th in the world on research output, publications, and patents (Universitas 21 n.d.). In 2021, Malaysia's Universiti Malaya was ranked 59th best university by the QS World University Rankings, based on reputation among academics, employability of graduates, and research citations (QS 2021). In the same ranking index, five Malaysian universities were ranked in the top 200 and total eight universities were in the top 500 best universities in the world. The Education Blueprint's 2025 goal is to achieve 1.1 million college places in three areas: technical vocational schools, private higher-level institutions, and online learning-in close collaboration with industry to ensure that supply of program graduates aligns with professional or labor demand. Malaysia's MOOC initiative-the Shift 9: Globalized Online Learningaims to enhance the quality of courses while lowering cost of delivery and showcasing Malaysian expertise through greater visibility of educational institutions. The policy mandate for credit transferability of MOOCs broadens access to tertiary education and expands learning opportunities toward the Education Blueprint's ambitious educational goals.

The development and use of online courses and MOOCs in Malaysia began in 2014. The first MOOC in Malaysia, taught by Taylor's University in 2013, received overwhelming registration and positive feedback from its participants. In September 2014, the Ministry of Higher Education launched the first four Malaysian MOOCs: offered by Universiti Kebangsaan Malaysia, Universiti Putra Malaysia, Universiti Teknologi MARA, and Universiti Malaysia Sarawak. To provide support to the rising growth of MOOCs among institutions of higher learning in Malaysia, the Malaysian Qualifications Agency (MQA), which serves as the national quality assurance and accreditation body, published the Guidelines on Credit Transfer for MOOCs in 2016. The guidelines provided reference to learners and institutions of higher learning on the implementation of awarding credits through massive open online courses.

Malaysia is the first country in the world to officially credit online courses and MOOCs as part of the national higher education policy. The path-breaking regulation establishes a precedent for modernizing the curriculum for higher education and encourages flexible learning among students by validating courses taken outside conventional classrooms. Credit transfer is allowed for up to $30 \%$ of the total graduating credits of a specific program of study within the Malaysian Qualifications Framework. Awarding of credits is based on a set of criteria: (i) quality of MOOCs and online course; (ii) authentication of applicant's identity; and (iii) verification of learning attainment over several types of learning assessments (oral, or online and in-person; written, or open or closed book; and proctored, either online or on-site). Most MOOCs developed their own learning assessments embedded in their design using either formative or summative methods; these types of MOOCs are called "verified courses." Where courses are not classified as "verified," higher education institutions could require testing outside the purview of the MOOC itself, following approval steps described in Figure 1, before the course credits could be awarded.

The approval of credit transfer in Malaysia follows a systematic process. Once the quality of course content and credit equivalency have been determined, the next step is to verify the identity of the learner. Successful course completion is confirmed through a variety of options: face-to-face proctoring, online proctoring, webcam proctoring, learning analytics, keystroke analysis, and other biometric authentication techniques; product assessment (evidence of work through products or artefacts, drawing, software, original published paper, etc.); and performance assessment (demonstration of skills or knowledge through onsite performances, presentations, role-play, etc.). 


\section{Figure 1: Malaysia's Approval Process for Credit Transfer of Massive Open Online Courses}

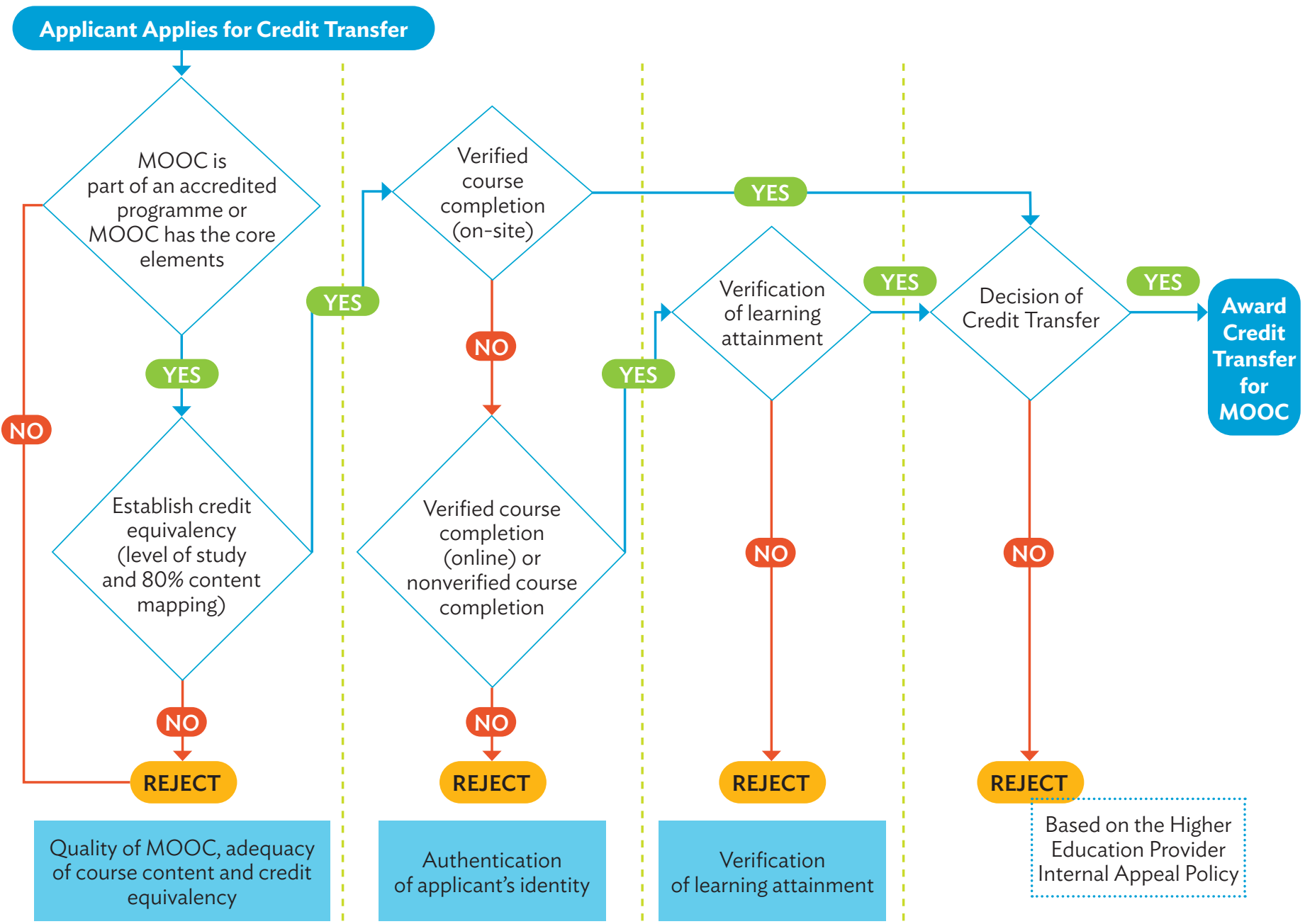

MOOC = massive open online course.

Source: Malaysian Qualifications Agency. 2016. Guidelines on Credit Transfer for MOOC. https://www2.mqa.gov.my/qad/garispanduan/2017/MOOC.pdf.

\section{B. India}

In the midst of the COVID-19 pandemic, India's new National Education Policy 2020 set out to restructure the course of schooling and higher education in India. The Higher Education Commission of India regulated higher education to increase gross enrollment from $26 \%$ in 2018 to $50 \%$ by 2040 . One of the enabling policies of the National Education Policy is to allow higher education institutions to offer online programs and open distance learning with proper accreditation, to enhance their offerings, improve student access, raise gross enrollment, and provide opportunities for lifelong learning. All open distance learning programs leading to a diploma or degree should meet the same standards as quality programs offered by on-campus learning. Top institutions accredited for online learning were encouraged and supported to develop top-notch online courses for integration into the curriculums of the higher education institutions.
Prior to the National Education Policy, the University Grants Commission (UGC) and the Ministry of Human Resource Development were responsible for the regulatory oversight of online learning, and their policies and regulations will remain in place until the National Education Policy 2020 can be fully established.

The SWAYAM online course platform was developed by the Ministry of Human Resource Development in 2016 in collaboration with the All-India Council for Technical Education (AICTE) and the National Program on Technology Enhanced Learning and the Indian Institute of Technology Madras, with the help of Google Inc. and Persistent Systems Ltd. By 2020, total enrollment in 1,300 of the platform's courses reached 16 million students in India (Class Central 2020). Demand for high quality MOOCs continues to grow, and India's 
online enrollment size is now second highest in the world, next to the US. This online course enrollment size represents a sizeable proportion of the 37 million tertiary education student population in the country and is an indicator of the positive impact driven by the enabling environment of granting credit-bearing online courses in the universities in the country.

The SWAYAM platform hosts all online courses, from those taught in grade nine until the postgraduate level, and may be accessed by anyone, anywhere, at any time. ${ }^{1}$ The UGC and AICTE played a key role in the implementation of the SWAYAM platform at the national level. The UGC and AICTE came out with the regulatory framework for conducting courses through online and open distance learning mode by higher education institutions. More than 1,000 faculty and instructors from across the country have been chosen within particular institutes or centers of learning to prepare these courses. Most universities do not have faculty who can prepare online courses; thus, only a select number initially offered online courses. The SWAYAM national coordinators that provide oversight to the process of online course selection include the following:

(i) National Program on Technology Enhanced Learning for engineering;

(ii) UGC for nontechnical postgraduate education;

(iii) Consortium for Educational Communication for undergraduate education;

(iv) National Council of Educational Research and Training and the National Institute of Open Schooling for school education;

(v) Indira Gandhi National Open University for out-of-school students;

(vi) Indian Institute of Management, Bangalore for management studies; and

(vii) National Institute of Technical Teachers Training and Research for teacher training programs.

Courses delivered through the SWAYAM platform are available for free to university students. To earn a certificate, learners must pass the final proctored exams conducted at designated centers. Universities and colleges approving transfer credit for these courses can use the marks and certificates obtained in the same courses.

In terms of course quality, the creation of platform courses follows a set of guidelines developed by the respective SWAYAM national coordinators to ensure that quality content is produced and delivered. Additionally, national coordinators have been appointed from key sectors, including India's centers of excellence and professional associations.
The 2016 UGC rules comprise the regulatory framework that issues credits for online learning courses through the SWAYAM platform by notifying universities to identify courses where credits can be transferred to students' academic records. These are done by gazette notification and subsequent adoption of these courses for credit transfer, as per amendments in the 2018 gazette notification (UGC India 2016). In 2021, the AICTE also provided guidelines covering aspects involved in the recognition given to higher education institutions with regard to institutional level eligibility criteria such as intake of students, infrastructure facilities available in the institutions and accreditation of existing courses, and credits for offering technical courses.

Only credit transfers for MOOCs and online courses are considered under the SWAYAM platform. Under the initial 2016 UGC regulations, the maximum transfer credit allowed for online courses was $20 \%$ per semester. This was later increased to $40 \%$ per semester in July 2020 (UGC 2020). The university where the student is enrolled (the parent institution) may not refuse credits to a student who completes and passes SWAYAM online courses, and below the $40 \%$ maximum transfer credit is allowed.

Evaluation and certification of MOOCs are done by a course's host institution, and its principal examiner is responsible for course evaluation. Evaluation should be based on a comprehensive review of student performance in online discussions and forums, and by quizzes, assignments, and a final exam. A certificate conferring successful completion of the MOOC needs to be signed by the principal examiner issued through the host institution and sent to the parent institution.

\section{Indonesia}

Indonesia's history of distance education is long, and growth has evolved since the 1950s (Pannen, Riyanti, and Ridwan 2019). Its earliest iterations were the correspondence schools, and before the introduction of online learning methods in 2014, went through locally developed MOOCs called Sistem Pembelajaran Daring Indonesia. The Indonesian Research and Education Network had the participation of 54 higher education institution course providers and 201 partner institutions. In 2019-2020, these schemes were consolidated into the ICE, which has become Indonesia's national online course marketplace and the main source of quality local and international courses for students.

Today, Indonesia has one of the world's most progressive regulatory frameworks for credit transfers because of online courses. At the onset of COVID-19, the shift in the higher education structure from on-campus learning to online delivery amplified the need for rigorous implementation of a regulatory policy toward

For more information, see SWAYAM. https://swayam.gov.in/about. 
online learning. Indonesia's strategic focus in this regard aims at access, quality, and relevance, particularly in tertiary education: (i) increasing tertiary education participation rates, promoting social equity; (ii) providing cost-effective solutions for the delivery of quality higher education, especially in higher education institutions in remote locations; (iii) promoting global access to transformative Industry 4.0 knowledge, skills, and innovations; and (iv) increasing access to lifelong learning opportunities and second-chance reskilling and upskilling of the workforce.

Two key national regulations underpin the current regulations for creditable online courses: the Ministry of Research and Technology and Higher Education Regulation No. 51 of 2018, and the most recent update under the reorganized Ministry of Education and Culture Regulation No. 7 of 2020. The key features of the new regulations include the following:

(i) transfer credit for online courses up to $40 \%$ of the total number of courses in a study program;

(ii) creation of the ICE, which is a consortium of universities for online education, as the country's marketplace for online courses;

(iii) development of a digital credentialing system enabled by blockchain ${ }^{2}$ technology to provide transparent and immutable mechanisms for tracking and sharing digital credentials and educational records, thus building trust among stakeholders for the true record of student achievement;

(iv) standardization of online learning provision for higher education institutions in (a) standards for online learning outcomes, (b) assessment methods, (c) credentials issuance, and (d) governance of online learning units within the tertiary institution; and

(v) quality assurance carried out internally and subject to regular monitoring, evaluation, and coaching throughout online learning.

The Indonesian ICE system is developed with a modern digital credentialing system enabled by blockchain technology. This system will help stamp out fake diplomas and diploma mills, and being immutable, the blockchain technology of encryptions will help develop trust in the system of accredited and verified issuers of credentials, while supporting students as they transition from school to the workplace. With this digital credentialing technology in place, students are able to source credit-bearing online courses from the ICE marketplace where curated courses are accredited. These courses are stacked alongside the courses they take from their own university to form up to $40 \%$ of all courses toward their chosen degree program. The Indonesian ICE online courses marketplace was launched in July 2021, with over 1,516 online course offerings to date, from 14 Indonesian national partner universities, and edX international content partner universities. ${ }^{3}$

\section{European Union}

Countries in the EU have long recognized the benefits of mobility and course credit transfers. Through its ECTS, higher education institutions in the EU credit academic qualifications and study periods in any of the 27 member countries as officially recognized and counted toward a qualification in any other EU member states (European Commission 2021). The ECTS is a learner-centered system for credit accumulation and transfer, based on the principle of transparency in teaching and assessment practices. It is a central tool in the Bologna Process, which aims to make national education systems more internationally similar and equivalent (European Commission 2020).

The ECTS system in place since 1989 has allowed a system of credit transfers used for in-person exchange system. The rising number of online courses since 2014 has allowed for the ECTS system to be used for online learning.

In the ECTS, credits may be granted both toward degree programs and for courses, and they articulate the volume of learning based on the defined learning outcomes and their associated workload. One credit equals 25-30 hours of course participation, including all learning activities such as lectures, seminars, projects, and practical work. In most countries in the EU, course workloads range from 1,500 to 1,800 hours per academic year; as such, 60 credits are allocated to the learning outcomes and associated workload during a full-time academic year or its equivalent. The correspondence of the full-time workload of an academic year to 60 credits is often formalized by national legal provisions (European Commission 2020).

In terms of awarding credits, national authorities determine which institutions have the right to award ECTS credits. Credits are awarded to individual students after they have completed the required learning activities and achieved the defined learning outcomes. Accumulation of credits may involve modules in both formal and informal educational situations. A student can accumulate credits to obtain qualifications as a requirement for the degree-awarding institution or to document personal achievements in the lifelong learning process (European Commission 2020).

2 A blockchain is a record of transactions that is digitally encrypted and thus, by design, is resistant to modification of data. For example, a blockchain can record the award of academic course credits by the university to a student. The name comes from its structure, in which individual records, called blocks, are linked together in a single list, called a chain. The original use of blockchain was in 2008 for the creation of the cryptocurrency called bitcoin, and since then has had many other applications, including digital credentialing. Blockchain has been described as an open, distributed ledger that can record transactions between two parties efficiently and in a verifiable and permanent way (lansiti and Lakhani 2017).

3 The edX online course platform (www.edx.org/) was created by MIT and Harvard in 2012, and was subsequently acquired by 2 U in 2021 . With over 40 million learners and over 120 million course enrollments as of 2021, edX is one of the largest providers of online courses in the world. 
In the transfer credit process, credits awarded in one context (program or institution) are recognized in another formal context for obtaining a qualification. This is key to successful learning and academic mobility within the EU context. Institutions, faculties, and departments have agreements that guarantee automatic recognition and qualification within regional and among country jurisdictions. For example, online courses developed by universities in the United Kingdom mounted on the FutureLearn platform can be used as independent academic credit toward a degree by a student in their home university, for example, the University of Amsterdam.

With the proliferation of MOOC platforms worldwide (e.g., Coursera, edX, and Udemy in the US; FutureLearn in the United Kingdom; Iversity in Germany; and Université Numérique in France), new channels for delivery of education powered by cloud computing, artificial intelligence, and machine learning have increased social mobility and ramped up academic mobility or the accessibility of learning. Students can now take courses and study anytime and anywhere, with the benefit of earning academic credits for eligible courses.

\section{COMMON MICROCREDENTIAL FRAMEWORK FOR CREDIT TRANSFERS}

An emerging trend in credentialing among MOOCs is microcredentials, which is basically mini-degrees or certifications in a specific topic area. In the US, Coursera coined the word "specialization certificate" to describe microcredentials, which is a collection of three or four courses to specialize in an area, for example "machine learning". To earn microcredentials, students identify competencies they want to master and complete the requirements to earn them. A huge number of these microcredentials have emerged to respond to specific skills that companies and hiring organizations demand. The edX calls these "micromasters" or "microbachelors" in their catalogue, while Udacity in Silicon Valley calls its microcredentials as "nanodegrees."

The European MOOCs Consortium launched the Common Microcredential Framework in 2020 to standardize learning workload and outcomes for MOOCs used in higher education and professional training. ${ }^{4}$ Co-funded by the EU's Erasmus+ Program, the Common Microcredential Framework aims to align standards with the European Qualifications Framework for Lifelong Learning so that the New Paradigms Recognition Project ${ }^{5}$ has a procedure to assess and validate academic recognition of MOOCs in the EU. A "traffic light" model is also used to assess the value of MOOCs under the European Network of Information Centers in the European Region and National Academic Recognition Information
Centers in the EU networks. The "traffic light" model, which is based on a number of factors of nonformal learning provision (such as identity verification, supervised assessment, quality assurance, etc.), aims to allow higher education institutions and employers to make an informed decision on whether to recognize achieved learning outcomes. The model can be used by learners to guide them on opting in or out of a MOOC if recognition is desired (Witthaus et al. 2016).

Since the ECTS has been in place for many decades, layering the Common Microcredentials Framework on top of its system and framework simplifies the job of MOOC credit transfers and speeds the scaling up of necessary functions. For microcredentials, MOOC courses need to satisfy certain requirements. First, one $\mathrm{MOOC}$ course must have total study time of no less than 100 hours and no more than 150 hours. This is the workload equivalent to 4-6 ECTS credits where 1 credit occupies $25-30$ hours study time. Second, online courses need to be classified at Level 6 to Level 8 within the European Qualifications Framework, or the equivalent levels established by the university's national requirement: bachelor's degree is Level 6, master's degree is Level 7, and the third cycle level is Level 8. ECTS credits can also be combined to recognize Level 4 and Level 5 of the European Qualification Framework. Recognition of MOOCs as formally qualified in the European Qualifications Framework enables student-centered, personalized learning through "stackable" criteria toward a degree or diploma.

\section{KEY FINDINGS}

India, Indonesia, and Malaysia are early adopters in formally recognizing online courses including MOOCs as earned credits for academic programs in addition to EU. Figure 2 summarizes the regulatory frameworks employed in the case studies considered in this brief. It focuses on the following six domains: (i) scope of credit transfer, (ii) quality assurance, (iii) assessment, (iv) academic recognition, (v) national qualification framework, and (vi) designated online course or MOOC provider. Among others, the following four points are key.

\section{(i) Accreditation of online courses for $30 \%-40 \%$ of total graduating credits}

India, Indonesia, and Malaysia accredit online courses including MOOCs-from $30 \%$ up to $40 \%$ of total graduating credits in a specific program of study. Malaysia was the first country in the world to adopt a national policy for crediting online courses including MOOCs. It issued enabling regulations and guidelines

4 Source: European MOOCs Consortium. n.d. Common Microcredential Framework. https://emc.eadtu.eu/images/EMC_Common_Microcredential_ Framework_.pdf.

5 The New Paradigms Recognition Project, an initiative implemented in 2016-2018 involving nine European countries, investigated new strategies and models in implementation of automatic recognition of course credits. This project assessed the outcomes of "eclectic learning" such as forms of E-learning and in-company training programs. It was funded by the Erasmus+ Program. 
Figure 2: Regulatory Frameworks - Credit Transfer of MOOCs-Online Courses Summary of the Case Studies
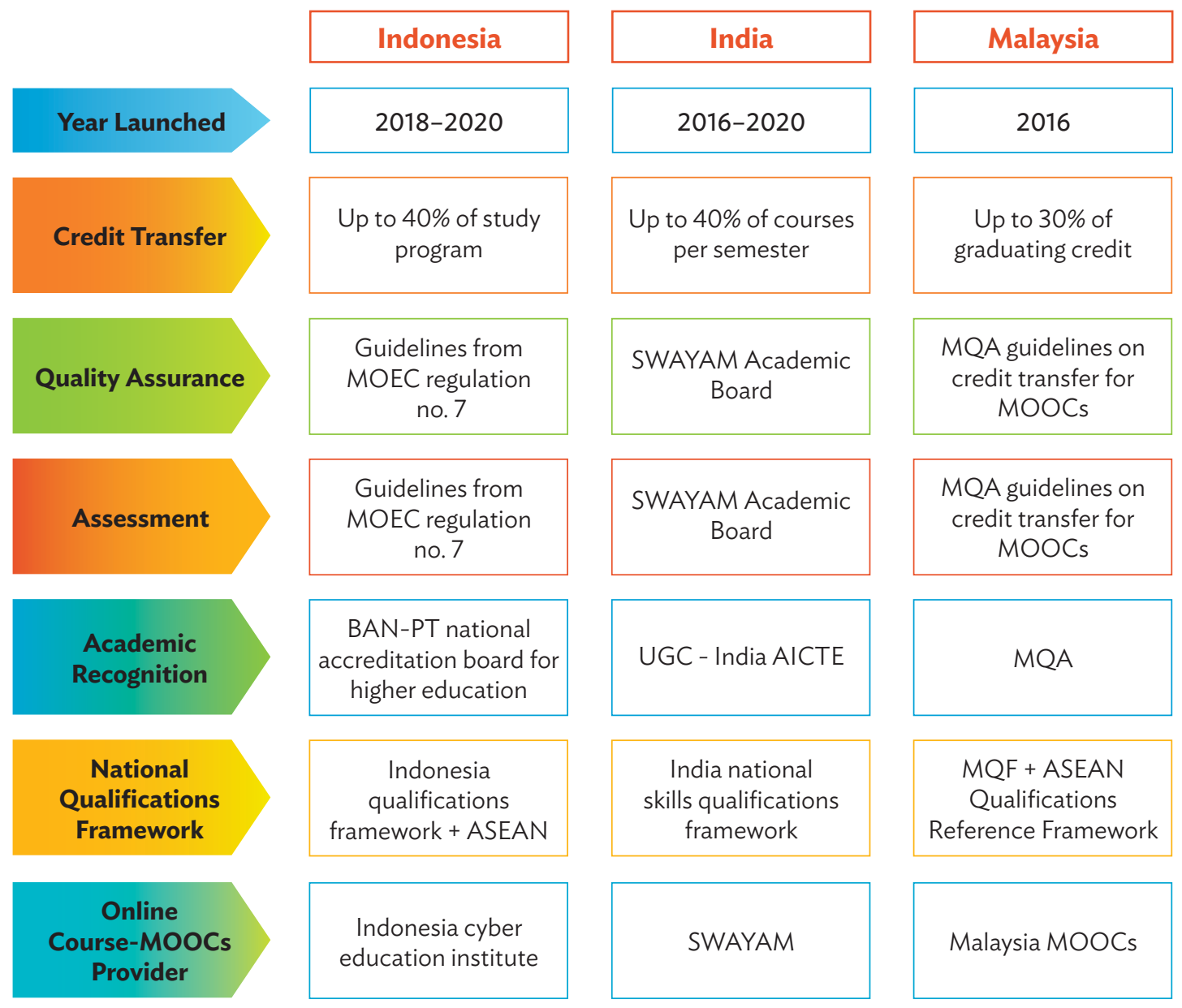

\begin{tabular}{|c|}
\hline European Union \\
\hline 2018 \\
\hline $\begin{array}{c}\text { Decision by individual } \\
\text { universities }\end{array}$ \\
\hline $\begin{array}{c}\text { European credit } \\
\text { transfer system and } \\
\text { microcredential framework }\end{array}$ \\
\hline $\begin{array}{c}\text { European Credit } \\
\text { Transfer and }\end{array}$ \\
Accumulation System \\
\hline $\begin{array}{c}\text { PARADIGMS ENIC- } \\
\text { NARIC-Academic } \\
\text { recognition info center }\end{array}$ \\
\hline $\begin{array}{c}\text { Consortium and } \\
\text { Universities }\end{array}$ \\
\hline $\begin{array}{c}\text { European } \\
\text { framework }\end{array}$ \\
\hline
\end{tabular}

AICTE = All India Council for Technical Education, ASEAN = Association of Southeast Asian Nations, BAN-PT = Badan Akreditasi Nasional Perguruan Tinggi, ENIC = European Network of Information Centers, MOEC = Ministry of Education and Culture, MOOCs = massive open online courses, $M Q A=$ Malaysian Qualifications Agency, MQF = Malaysian qualifications framework, NARIC = National Academic Recognition Information Centers, PARADIGMS = New Paradigms in Recognition Project, UGC = University Grants Commission, SWAYAM = Study Webs of Active-Learning for Young Aspiring Minds.

Source: Authors' representation.

in 2016, with a mandate to allow up to $30 \%$ of all graduating course credits in universities to be sourced from online courses and MOOCs. In the same year, UGC in India issued regulations that allowed university students to use online courses and MOOCs from SWAYAM. University students in India could obtain credit-conferring courses online from the portal to count for up to $20 \%$ of credits per semester; and in 2020 the UGC raised this cap to $40 \%$. In Indonesia, regulations first established in 2018 and then reissued in 2020 allowed up to $40 \%$ of courses in a study program to be taken online and be eligible for course credit.
Notably, the desire to issue such regulations was preceded by government policy development. Malaysia's initiative launched the Education Blueprint 2015-2025, in which Globalized Online Learning sought to bring Malaysian expertise to the world to increase its role in world commerce. Indonesia's modernization of education aims to make the economy competitive in the world market and generate Industry 4.0 technologies quickly through online learning technologies. 


\section{(ii) \\ Quality assurance mechanisms in recognizing credit for online courses}

Regulatory frameworks and detailed guidelines are implemented to ensure quality. The EU member states use the ECTS for quality assurance in vetting online courses, but detailed quality assurance mechanisms for awarding credits is done by the universities that issue the credentials.

In Malaysia, the Malaysian Qualifications Agency prepares detailed guidelines for accreditation of MOOCs, which is by far one of the most comprehensive practices for awarding course credits. In its scheme, requirements for credit transfers of MOOC and online courses include the level of program, conditions for credit transfer eligibility, limits of credit transfer, criteria for awarding credit transfer, authentication of credit transfers, and verification of learning attainment, within detailed compliance procedures for credit transfers. The Malaysian Qualifications Agency guidelines provide an excellent model for other countries in credit recognition processes for online courses. In a recent development, in May 2021, MQA has issued a policy that allows grade transfer of MOOC and online courses, which is expected to further promote the implementation of MOOC in the country.

\section{(iii) National qualifications frameworks: An enabling feature in recognition of credit}

The EU, India, Indonesia, and Malaysia have national or regional qualifications frameworks that support the framing of regulations and award criteria, whereby the credits awarded are in line with the qualifications gained by the student. India has a National Skills Qualifications Framework that addresses the mobility between general education and vocational education. Indonesia has the national Indonesian Qualifications Framework, which adheres to the Association of Southeast Asian Nations (ASEAN) Qualifications Reference Framework. The Malaysia Qualifications Framework likewise adheres to the ASEAN Qualifications Reference Framework. The EU member states have a separate regional European Qualifications Framework, which is used in these countries on top of their respective national qualifications frameworks.

\section{(iv) Providers of online courses and massive open online courses}

India has the most explicit stipulations about where students can discover and access credit-bearing online courses and MOOCs. The Ministry of Human Resource Development built the SWAYAM online course platform, which is mandated to accredit and post online courses including MOOCs in coordination with nine national agencies and centers of excellence consisting of universities and professional associations. In the EU, the sources of online courses include the European MOOCs Consortium, which includes providers like FutureLearn in the United Kingdom and Université Numérique in France; and other independent, higher education institutions outside of the consortium. Indonesia created ICE to be its online course marketplace for Indonesian university courses, but now also includes global course platform providers as part of ICE offerings. Malaysia has its own MOOC platform.

\section{LESSONS FOR COUNTRIES CONSIDERING CREDIT TRANSFER OF ONLINE COURSES}

This brief examines the experiences of the early adopters in recognizing online courses and MOOCs as qualifying for earned credits on higher education programs. To reap the social and economic rewards of engagement in online learning, which was accelerated dramatically by the COVID-19 pandemic, it is essential for governments and institutions to adopt enabling policy frameworks that promote credits from online courses including MOOCs to be recognized and transferrable across higher education institutions. Furthermore, countries contemplating on adopting these enabling policy frameworks would benefit from the experiences of the early adoptersthe EU, India, Indonesia, and Malaysia-by examining the underlying procedures and quality assurance mechanisms they used, including student learning assessment methods and credit awarding processes and enforcement, then adapting these to their own institutional environment. The small countries may not have the capacity to develop these online courses and regulations, but the EU case shows the potential for regional cooperation.

The road to wider acceptance of credit transfers of online courses will be bumpy, and challenges are many. Since accreditation is a formal process of quality control, it differs by context and mode of learning; therefore, some standardization is required to be effective. Clear procedures of credit award need to be in place, such as those prescribed by the Malaysian system and the ECTS.

Concerns about quality of online courses vary from one provider to another. Thus, the challenge of figuring out the quality of online courses and their alignment with the curriculum in the home institution are major tasks. Who is responsible for the assessments of any given course or program, for example? There is a need to determine if the provider and online course program belong to the system of higher education in the country, or from authoritative sources of information. The development of country online platforms such as SWAYAM in India, and ICE in Indonesia, provides the initial experiences of filters for quality of courses. Furthermore, the relevance of the available online courses to the country's current economy, culture, and social and political contexts would need to be a priority in curating offerings in a country platform for online courses. 


\section{REFERENCES}

Arizona State University Action Lab and Boston Consulting Group. 2018. Making Digital Learning Work: Success Strategies from Six Leading Universities and Community Colleges.

https:/edplus.asu.edu/sites/default/files/BCG-MakingDigital-Learning-Work-Apr-2018\%20.pdf.

Class Central. 2020. By the Numbers: MOOCs in 2020. https://www.classcentral.com/report/mooc-stats-2020/.

European Commission. European Credit Transfer and Accumulation System 2021. https://ec.europa.eu/education/ resources-and-tools/european-credit-transfer-andaccumulation-system-ects_en.

2020. The Bologna Process and the European Higher Education Area. https://ec.europa.eu/education/policies/ higher-education/bologna-process-and-european-highereducation-area_en.

. European Credit Transfer and Accumulation System (ECTS). https://ec.europa.eu/education/resources-and-tools/ european-credit-transfer-and-accumulation-system-ects_ en.

European MOOCs Consortium. n.d. Common Microcredential Framework. https://emc.eadtu.eu/images/EMC_Common_ Microcredential_Framework_.pdf.

S. Galloway. 2021. Post Corona: From Crisis to Opportunity. Portfolow. https://nextbigideaclub.com/magazine/postcorona-crisis-opportunity-bookbite/26434/.

Government of Indonesia, Ministry of Education and Culture. 2020. Regulation No. 7 of the Minister of Education and Culture. https://jdih.kemdikbud.go.id/arsip/Salinan $\% 20$ PERMENDIKBUD\%207\%20TAHUN\%202020\%20FIX.pdf.

Government of Japan, Ministry of Education, Culture, Sports, Science and Technology (MEXT). 2020. Impact of COVID-19 Pandemic on HE and MEXT's Main CountermeasuresStarting Period for Classes and Promotion of Utilization of Distance Learning. Tokyo. https://www.mext.go.jp/en/ content/20200707-mxt_kokusai_000005414_02.pdf.

Government of Malaysia, Ministry of Education. 2015. Malaysia: Education Blueprint 2015-2025 (Higher Education). https://www.kooperation-international.de/uploads/ media/3._Malaysia_Education_Blueprint_2015-2025_Higher_Education__.pdf.

R. Hayashi et al. 2020. Online Learning in Sri Lanka’s Higher Education Institutions during the COVID-19 Pandemic. ADB Briefs. No. 151. Manila: Asian Development Bank.

M. lansiti and K. Lakhani. 2017. The Truth About Blockchain. Harvard Business Review. Massachusetts: Harvard University. https://web.archive.org/web/20170118052537/https:/hbr. org/2017/01/the-truth-about-blockchain.
International Labor Organization. 2020. Youth and COVID-19: Impacts on Jobs, Education, Rights and Mental Well-being. Geneva.

International Monetary Fund. 2020. Global Economic Outlook. Washington, DC.

Malaysian Qualifications Agency. 2016. Guidelines on Credit Transfer for MOOC. Kuala Lumpur. https://www2.mqa.gov. my/qad/garispanduan/2017/MOOC.pdf.

P. Pannen, R. D. Riyanti, and Ridwan. 2019. Indonesia Cyber Education Institute: Assuring Quality of Online Education in Indonesia. In Proceedings of Institute of Academic Education International Academic Conference on Teaching, Learning and E-learning. 25 October 2019. Czech Institute of Academic Education z.s., Dresden, Germany.

Qingdao Declaration. 2015. International Conference on ICT and Post-2015 Education: Seize Digital Opportunities, Lead Education Transformation. Qingdao, People's Republic of China. ED/PLS/ICT/2015/01.UNESCO. https:/unesdoc. unesco.org/ark:/48223/pf0000233352?posInSet=1\&queryld $=\mathrm{N}-$ EXPLORE-6285930e-49bd-4f3d-8f16-58bc878b093f.

QS. 2021. Out Now: QS World University Rankings by Subject 2021. 3 March. https://www.topuniversities.com/universityrankings-articles/university-subject-rankings/out-now-qsworld-university-rankings-subject-2021.

SWAYAM. About SWAYAM. https://swayam.gov.in/about.

UGC India. 2016. Credit Framework for Online Learning Courses through Study Webs of Active Learning for Aspiring Minds: Regulation, 2016. https://storage.googleapis.com/swayam1pub-data/wqimgtest_def7ed99-3086-48a1-9148a0dc7ab7d461.pdf. 2020. Public Notice (Expression of Interest). https://www.ugc. ac.in/pdfnews/4981711_Public-Notice-EOI.pdf.

UNESCO. 2020. A Practical Guide to Recognition: Implementing the Global Convention on the Recognition of Qualifications Concerning Higher Education. ED/E30/HED/02. https://unesdoc.unesco.org/ark:/48223/pf0000374905. 2021. COVID-19 Impact on Education. UNESCO-Paris. https://en.unesco.org/covid19/educationresponse.

Universitas 21. n.d. U21 University Rankings 2020. https://universitas21.com/.

G. Witthaus et al. 2016. Validation of Non-formal MOOC-based Learning. JRC Science for Policy Report. Brussels: European Commission. 
About the Asian Development Bank

ADB is committed to achieving a prosperous, inclusive, resilient, and sustainable Asia and the Pacific, while sustaining its efforts to eradicate extreme poverty. Established in 1966, it is owned by 68 members49 from the region. Its main instruments for helping its developing member countries are policy dialogue, loans, equity investments, guarantees, grants, and technical assistance.

ADB Briefs are based on papers or notes prepared by ADB staff and their resource persons. The series is designed to provide concise, nontechnical accounts of policy issues of topical interest, with a view to facilitating informed debate. The Department of Communications administers the series.
The views expressed in this publication are those of the authors and do not necessarily reflect the views and policies of ADB or its Board of Governors or the governments they represent. ADB encourages printing or copying information exclusively for personal and noncommercial use with proper acknowledgment of ADB. Users are restricted from reselling, redistributing, or creating derivative works for commercial purposes without the express, written consent of ADB.

Asian Development Bank

6 ADB Avenue, Mandaluyong City

1550 Metro Manila, Philippines

Tel +63286324444

Fax +63286362444

www.adb.org/publications/series/adb-briefs

(c) (1)

(C) 2021 ADB. The CC license does not apply to non-ADB copyright materials in this publication.

https://www.adb.org/terms-use\#openaccess http://www.adb.org/publications/corrigenda pubsmarketing@adb.org 